\title{
Appraisal of Aggregate Technical, Commercial and Collection Losses in Nigerian Electricity Distribution System
}

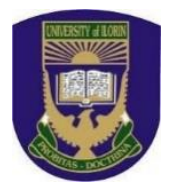

\author{
U. A. Dodo ${ }^{1 *}$, M. N. Nwohu², I. N. Abubakar' ${ }^{2}$, M. A. Dodo ${ }^{3}$ \\ ${ }^{1}$ Department of Electrical and Computer Engineering, Baze University Abuja, Nigeria. \\ ${ }^{2}$ Department of Electrical and Electronics Engineering, Federal University of Technology Minna, Nigeria. \\ ${ }^{3}$ Department of Electrical Engineering Technology, Federal Polytechnic Bida, Nigeria.
}

\begin{abstract}
From a practical point of view, no power system is free of losses. Power system losses, especially in distribution systems are usually high and result in increasing the cost of operations to the electric utilities and the price tag of electricity to the consumers. Aggregate Technical, Commercial and Collection (ATC\&C) losses is a reliable parameter that reveals the true energy and revenue loss conditions of distribution systems. In this paper, mathematical models were developed for the determination of billing efficiency, collection efficiency, and ATC\&C losses using Life Camp Area Office's network of Abuja Electricity Distribution Company Plc Nigeria, as a case study. The average billing efficiency, collection efficiency and ATC\&C losses for the period under review were found to be $89.73 \%$, $84.80 \%$, and $23.79 \%$ respectively. An understanding of appraisal of these losses is important to the power system Engineers, energy policy makers, and the power firms as it enables areas of high losses in the network to be identified, which will give room for credible investment plans and subsequent monitoring of the losses.
\end{abstract}

KEYWORDS: ATC\&C losses, billing, energy, distribution system, revenue

[Received October 3, 2018, Revised March 3, 2019, Accepted June 24, 2020]

Print ISSN: 0189-9546 | Online ISSN: 2437-2110

\section{INTRODUCTION}

With the power generating stations sited far from the consumers, it is essential to step up the generated voltage to higher levels for transmission (Ayamolowo et al, 2019). Electrical distribution is the last stage in the delivery of electricity to consumers. In developed countries, electricity distribution to residential and commercial customers is done via underground distribution feeders through compact transformers for the final service connections to each home or business centre. In rural settlements, electricity distribution is done via overhead lines.

Power system losses are wasteful energy resulting from internal or external factors, and dissipation of energy in the system, and they include losses incurred between sources of power and consumers, losses due to resistance, energy theft, and miscalculations (Anumaka, 2012). This results in an increase in the cost of operations to the power utilities and the price tag of electricity to the customers. Power system losses especially, the Transmission and Distribution losses cost the U.S. approximately $\$ 9$ billion each year (Inan et al, 2014). In Nigeria, more than $50 \%$ of the power generation is recorded as loss, and this generation is insignificant as it is not even up to $30 \%$ of the national demand (Komolafe and Udofia, 2020). Furthermore, the power system losses in the country are rising by at least 474 billion annually according to the study conducted by the French Agency for Development (FAD) and supported by the European Union (Okechukwu, 2019).

The distribution system being the last stage in power delivery, is the revenue generation subsector of the electricity

*Corresponding author: usman.dodo@bazeuniversity.edu.ng supply industry. More so, it is the most visible and most opened to the critical assessments of its users. Unfortunately, it is the frailest and accounts for the highest losses in the power sector value chain (Sandhu and Maninder, 2013). Thus, despite the struggle by the power generation subsector to meet up with the ever-increasing electricity demands, the distribution subsector has been enmeshed in losses (Alam et al, 2014).

There are various forms of losses associated with distribution systems. There are losses due to heat dissipation, transformation losses, billing errors, metering errors, energy theft, etc. According to (Anumaka, 2012; Alamin, 2012), losses in the power system can be evaluated using some formulae in respect of configurations of loads and generation, by computation of $I^{2} R$, B-Loss Coefficient, differential power loss, computation of power losses by line flows, and Dopezo transmission loss formula. Anumaka (2012) further proposed another method known as the "Loss factor approach". However, a parameter that was widely used in the past years to represent power system losses is referred to as the Transmission and Distribution (T\&D) losses (Singh, 2013).

The major weakness of using "T\&D" losses as an index to signify losses in the power system is that it assumes bills delivered to electricity consumers as accumulated income and not the actual money collected. That is, it does not capture the gap between the collection and the billing, notwithstanding the energy theft in large amounts not considered or captured in the billing (Power Distribution Management, 2016). In other words, the major drawback of considering "T\&D" losses as a parameter for evaluating losses of the power system is that, it

doi: http://dx.doi.org/10.4314/njtd.v17i4.6 
represents only the losses due to dissipation of heat whereas there are other facets of losses such as billing errors, poor metering, incorrect meter reading, theft and so on which are otherwise referred to as non-technical losses (Singh, 2013; Mam et al, 2014). Appraisal of these power system losses is of utmost importance since they are inevitable no matter how carefully the power systems are designed (Nwohu et al, 2017). Measures can be taken to minimize these losses if there is a genuine baseline for their appraisal and this will lead to the efficient and effective operation of the whole system, with gross reductions in the cost of operations to the utilities (Anumaka, 2012), and gross reduction in the price tag of energy to the consumers.

Aggregate Technical and Commercial (AT\&C) losses are a reliable parameter adopted by utilities in a scenario, where the power system is characterized by losses due to different factors (Singh, 2013; Mam et al, 2014). The Aggregate Technical and Commercial (AT\&C) losses were presented as a solution for this circumstance by the electricity regulatory commission of India as it depicts a complete picture of distribution system losses (Singh, 2013; Khobragade and Meshram, 2014; Mam et al, 2014; R-APDRP, 2009). In Nigeria, this concept is known as Aggregate Technical, Commercial and Collection (ATC\&C) Losses (NERC, 2015). Technical losses signify the losses due to the apparatus used in the electricity transmission and distribution, commercial losses occur when the billing process could not account for all billable energies, while the collection losses occur when the utilities fail to recover revenues from electricity consumers in consonance with the billed amount (Independent Energy Watch Initiative, 2016).

In this research, mathematical models will be formulated for computation of billing efficiency, collection efficiency, and ATC\&C losses for a period of six months using Life Camp Area Office's network of Abuja Electricity Distribution Company (AEDC) Plc Nigeria, as a case study.

\section{REVIEW OF ATC\&C LOSSES}

The concept of ATC\&C losses was adopted in the MultiYear Tariff Order (MYTO-2.1) by the Nigerian Electricity Regulatory Commission (NERC) during the process of privatization of distribution companies (disco) in 2013. It was part of the foremost benchmarks for deciding on the favourite bidders. Thus, consideration of the most aggressive and achievable ATC\&C loss reduction trajectory over a period of five-year. The yearly loss reduction profile based on yearly percentage commitment by each distribution company during privatization is shown in Table 1 (NERC, 2015).

It is further clarified in NERC (2015) that, at the time of the conclusion of the sale and subsequent handover of the utilities to core investors in the year 2013, the exact ATC\&C loss figure for each of the distribution companies had not been ascertained.
Table 1: Nigerian DisCos relative ATC\&C losses reduction commitment per year.

\begin{tabular}{lccccc}
\hline $\begin{array}{l}\text { Distribution } \\
\text { Company }\end{array}$ & $\begin{array}{c}\text { Year 1 } \\
(\boldsymbol{\%})\end{array}$ & $\begin{array}{c}\text { Year 2 } \\
(\boldsymbol{\%})\end{array}$ & $\begin{array}{c}\text { Year 3 } \\
(\boldsymbol{\%})\end{array}$ & $\begin{array}{c}\text { Year 4 } \\
(\boldsymbol{\%})\end{array}$ & $\begin{array}{c}\text { Year 5 } \\
(\boldsymbol{\%})\end{array}$ \\
\hline Abuja & 31.50 & 23.80 & 7.10 & 10.90 & 15.50 \\
Benin & 18.00 & 20.00 & 22.59 & 25.00 & 20.00 \\
Enugu & 0.63 & 25.30 & 28.37 & 36.47 & 43.33 \\
Ibadan & 16.00 & 18.71 & 20.43 & 19.84 & 16.61 \\
Jos & 10.30 & 9.04 & 11.01 & 17.82 & 24.21 \\
Kaduna & 33.00 & 37.00 & 38.00 & 38.00 & 38.00 \\
Kano & 15.00 & 23.00 & 25.00 & 22.00 & 15.00 \\
Eko & 27.00 & 26.93 & 20.94 & 10.16 & 3.77 \\
Ikeja & 25.70 & 26.90 & 28.95 & 18.50 & 9.20 \\
Port Harcourt & 15.00 & 17.50 & 20.00 & 20.00 & 17.00 \\
Yola & 25.17 & 16.14 & 13.81 & 12.06 & 8.85 \\
\hline
\end{tabular}

Aggregate Technical, Commercial and Collection losses comprise technical losses, commercial losses and shortage resulting from failure to collect the total amount of money billed (Kirankumari et al, 2013). It is the aggregate of the Transmission and Distribution (T\&D) losses and loss due to failure to realize all payable demands (Gosh, 2012). Three elements constitute ATC\&C losses. Thus, technical losses, commercial losses and collection losses.

\section{A. Technical Losses}

The technical losses mostly occur due to high $\mathrm{I}^{2} \mathrm{R}$ losses on distribution lines, transformation losses, inadequate planning and design, overloading or overstressing of substation equipment, apparatus, and existing lines, and lack of upgrading of old equipment and lines (R-APDRP, 2009; Shahi, 2011). The level of technical losses varies with the transformation capacity of transformers, type of conductors used, and reactive loads among other factors. The total distribution feeder energy loss can generally be expressed as the difference between energy fed into a network and the energy consumed (Mahmood et al, 2014), as shown in Eqs. (1) - (3).

$$
\begin{aligned}
& P_{T}=\beta+\tau \\
& \beta=\lambda-\varepsilon+\rho \\
& \tau=\sigma-\gamma
\end{aligned}
$$

where:

$P_{T}$ is the total distribution feeder loss, $\beta$ is the high tension feeder loss, $\tau$ is the low tension feeder loss, $\lambda$ is the input energy to high tension feeder, $\varepsilon$ is the export energy from low tension feeder, $\rho$ is the consumers billed energy, $\sigma$ is the energy input to the low tension feeder, and $\gamma$ is the billed energy of low tension consumers respectively.

\section{B. Commercial Losses}

These are illegal consumption of electrical energy which are not correctly billed or metered. The commercial losses are basically attributed to anomalies in metering, meter reading, and theft by direct connection to the line (Khobragade and Meshram, 2014; Shahi, 2011). Losses through metering are in the form of zero consumption in meter folio resulting from untraceable consumers, inaccessible premises, stopped, or defective meters. Meter tampering in different manners; bypassing of meters; use of magnets to slow down the meters; damaging or altering of current and/or potential transformer 
circuits or ratios, and unauthorized resetting of meters are generally related to commercial losses through metering. The most visible and common form of commercial losses is the theft of energy by direct connection to the low tension lines.

\section{Collection Losses}

In a billing cycle, a distribution utility issues bills against consumed energy. In most cases, however, the utility is not able to realize the complete amount of money billed by it. The ratio of the total amount of money collected to the total amount of money billed is referred to as collection efficiency, and when it is low implies high collection losses (Gosh, 2012; R-APDRP, 2009; Shahi, 2011). The functional process, measurement, and topology of loss measurement of ATC\&C losses are demonstrated in Figure 1 using a block diagram.

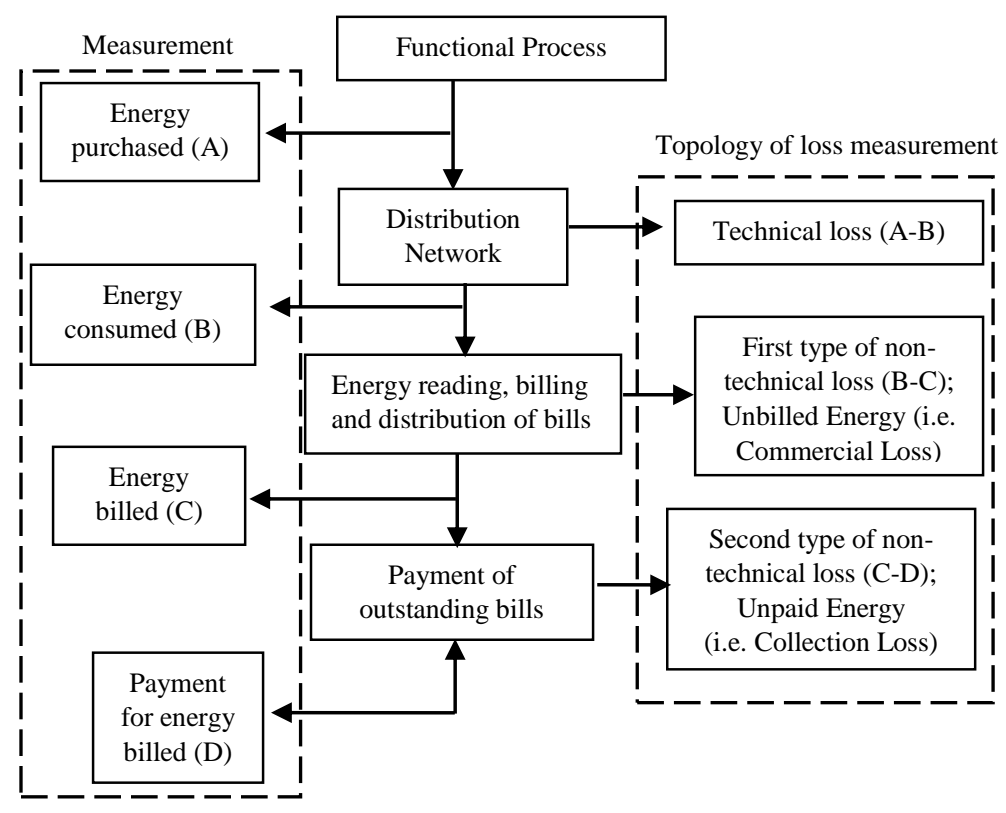

Figure 1: The functional process, measurement, and topology of loss measurement of ATC \& C losses (Kirankumar et al, 2013).

The block diagram captures the vital modules of ATC\&C losses and is interpreted with respect to the components, both at the physical level of transmission and distribution and the revenue generation phase. Hence, the ATC \&C losses can be evaluated using the relation (Gosh, 2012; R-APDRP, 2009; Shahi, 2011; Nwohu, et al, 2017).

$$
\operatorname{ATC} \& C \text { Losses }(\alpha)=\{1-(\Gamma \times \delta)\} \times 100 \%
$$

where, $\Gamma$ and $\delta$ are the billing efficiency and collection efficiency as expressed in Eq.s (5) and (6) respectively.

$$
\begin{aligned}
& \text { Billing Efficiency }=\frac{\text { Net Energy Billed }}{\text { Net Input Energy }} \\
& \text { Collection Efficiency }=\frac{\text { Net amount of money collected }}{\text { Net amount of money billed }}
\end{aligned}
$$

\section{Related Studies on Analysis of Losses in Distribution Network}

Power system losses are very important in the distribution network because these losses have an impact on the available power at the customer location and cost of operation. Due to the impact of losses on the distribution network, many researchers have analyzed and developed tools to understand and reduce the impact of the different types of losses on the distribution network. Nwohu et al (2017) proposed a feederwise approach for analysis of ATC\&C losses in a Nigerian distribution system. Configuration of feeders and their nomenclatures in the network area was studied and based on that, mathematical relations were formulated for computation of ATC\&C losses. Amaranatha et al (2015) presented a method of optimal placement of capacitors to distribution transformers to reduce energy loss in distribution systems.

In analyzing the radial distribution system to establish the extent of losses, a transformer was electrically modelled and represented by resistance and reactance respectively, while the distribution network was presumed to be a balanced threephase network with zero current harmonics. The power loss on the conductor was disintegrated into two parts, one produced by the reactive current and the other by the real current. The power loss factor was computed bearing in mind a section of the previous load profile over a definite period collated from the metering historical register, and the power loss at each point in time was computed by running power flow. Alam et al (2014) presented a broad analysis of AT\&C Losses occurring in the power distribution system with distinctive emphasis on loss mitigation and power supply efficiency improvement. Mahmood et al (2014) conducted a study on the analysis of technical losses and impacts in the distribution system.

Using Electromagnetic Transient Analysis Program (ETAP), technical losses due to the properties of material and opposition to the flow of electric current in the power distribution system were simulated and analyzed. As a result, maximum losses for each of the equipment were presented. Anumaka (2012) explicitly discussed various methods of mathematical analysis of power system losses. The methods are by; computing $I^{2} \mathrm{R}$ losses, differential power loss, using the B-Loss coefficient, analysis of system parameters, and simulation of load flow. Preferences were given to the B-Loss coefficient and another method referred to as Dopezo methods as those producing more dependable results.

Navani et al (2014) analyzed a typical distribution system consisting of eight $11 \mathrm{kV}$ feeders supplying both rural and urban settlements, to establish the extent of technical and non-technical losses using MATLAB simulation. Out of the eight feeders, only one was considered for ease of analysis. The distribution loss of the project area was found to be $29 \%$. Sandhu and Maninder (2013) analyzed technical and nontechnical losses and their economic consequence in the power sector. The electrical network of the studied case was modelled and simulated using MATLAB. The method of Newton Raphson load flow was adopted to determine technical losses. The total energy supplied and total energy billed were thoroughly measured for a full month, and their differences 
were used to establish the amount of losses in that area. Rakhra (2013) presented an analysis of various types of distribution losses of radial distribution networks.

The study considered 6-number $11 \mathrm{kV}$ feeders metered at the substations to capture energy consumptions. The difference between the energy usage at the beginning of the period and the accrued energy at the end of that period gave the cumulative energy consumption during the period. The total technical (distribution and transmission) and nontechnical losses were calculated by first summing up the units consumed and deducted from the actual allocated units.

\section{MATERIALS AND METHODS}

In this research, the customers are grouped into two categories of Maximum Demand (MD) and non-Maximum Demand (non-MD). MD customers have maximum demands of at least $45 \mathrm{kVA}$ while non-MD customers have maximum demands below $45 \mathrm{kVA}$. All MD customers have been metered while some of the non-MD customers are not provided with meters yet, hence they rely on estimation to settle their electricity bills. All the meters are read at every billing cycle including the statistical meters installed at the boundary of the Area Office's network. The main objective of these boundary meters is to technically determine the amount of export and import of energy, and commercially segregate electricity consumption at various Area Offices of the distribution processes for proper allocation of sales, revenue and system losses. According to the earlier grouping of the customers, a mathematical model is formulated for analysis of ATC\&C losses of the case chosen using the data on energy delivered, energy billed, and revenue generated for a period of six months (July 2019 to December 2019).

\section{A. Study Location}

The case chosen for this study is Life Camp Area Office's network under Abuja Electricity Distribution Company (AEDC) Plc, Nigeria. The Area Office is located on latitude $9^{\circ} 3^{\prime} 41.328^{\prime \prime} \mathrm{N}$ and longitude $7^{\circ} 24^{\prime} 11.376 " \mathrm{E}$. AEDC Plc is one of the eleven privatized electricity distribution companies in Nigeria that operates in Kogi State, Nasarawa State, Niger State, and the Federal Capital Territory (FCT). Life Camp Area Office, under FCT, has six Service Centers with a customer population of 22,316 comprising 205 MD customers, 13,524 metered, and 8,587 unmetered non-MD customers. The Service Centers (Mbora, Life Camp, Karmo, Gwagwa, Jiwa, and Saburi) perform network maintenance and revenue collection of the area office. The satellite view of the network area is shown in Figure 2.
B. Model for Evaluation of Loss Parameters of the Network Area

Here, the billing efficiency, collection efficiency, and ATC\&C losses are computed using the mathematical models developed according to the cluster of customers described in section III.

\section{1.) Net input energy}

The net input energy $(\mu)$ is the difference between the total energy received $\left(E_{\text {in }}\right)$ and the total energy exported $\left(E_{\text {out }}\right)$ from the network area given as:

$$
\mu=E_{\text {in }}-E_{\text {out }}=\sum_{i=1}^{\infty} K_{i}-\sum_{j=1}^{\infty} M_{j}
$$

where:

$K_{i}(i=1,2,3,4 \ldots \omega)$ stands for the boundary meters registering import of energy, $M_{j}(j=1,2,3,4 \ldots \omega)$ stands for the boundary meters registering energy exported from the network, and $\omega$ is the number of feeders in the network.

\section{2.) Billed energy of the network area}

The algebraic sum of the total energy billed on MD customers $\left(\mathrm{E}_{\mathrm{B} 1}\right)$, metered non-MD customers $\left(\mathrm{E}_{\mathrm{B} 2}\right)$, and unmetered non-MD customers $\left(\mathrm{E}_{\mathrm{B} 3}\right)$ gives the net energy sales/billed $\left(\mathrm{N}_{\mathrm{EB}}\right)$ in the network area. Thus,

$$
\begin{aligned}
N_{E B} & =\sum_{i=1}^{n=3} E_{B i} \\
E_{B 1} & =\sum_{i=1}^{n} A_{i} \\
E_{B 2} & =\sum_{j=1}^{n} B_{j} \\
E_{B 3} & =\sum_{k=1}^{n} C_{k}
\end{aligned}
$$

where:

$A_{i}(i=1,2,3,4 . . n)$ is the energy billed on MD customers, $B_{j}(j=1,2,3,4 . . n)$ is the energy billed on metered non-MD customers, $C_{k}(k=1,2,3,4 . . n)$ is the energy billed on unmetered non-MD customers, and $\mathrm{n}=$ number of customers in the network area respectively. 


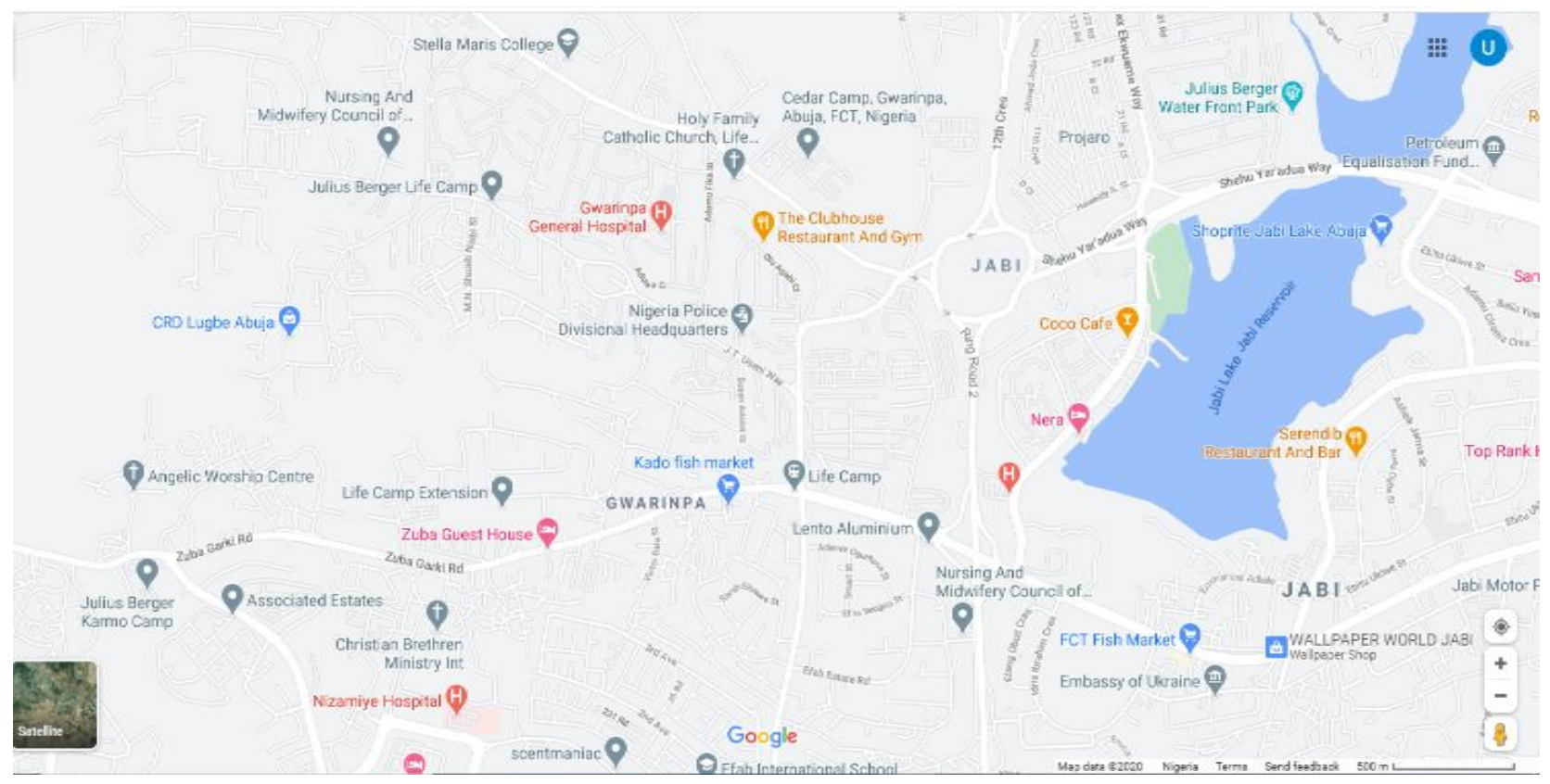

Figure 2: Satellite view of case study office network area.

\section{3.) Billing efficiency of the network area}

The ratio of net energy sales/billed $\left(\mathrm{N}_{\mathrm{EB}}\right)$ to net input energy $(\mu)$ of the network area is known as the billing efficiency. From Eq.s (7) and (8), the billing efficiency $(\Gamma)$ is obtained as;

$$
\Gamma=\frac{N_{E B}}{\mu}=\frac{\sum_{i=1}^{n=3} E_{B i}}{\sum_{i=1}^{\omega} K_{i}-\sum_{j=1}^{\omega} M_{j}}
$$

\section{4.) Amount of money billed in the network area}

The algebraic sum of the total amount of money billed on MD customers $\left(A_{B 1}\right)$, metered non-MD customers $\left(A_{B 2}\right)$, and unmetered non-MD customers $\left(A_{B 3}\right)$ gives the net amount of money billed $\left(\mathrm{N}_{\mathrm{AB}}\right)$ in the network area. Thus,

$$
\begin{gathered}
N_{A B}=\sum_{m=1}^{n=3} A_{B m} \\
A_{B 1}=\sum_{i=1}^{n} D_{i} \\
A_{B 2}=\sum_{j=1}^{n} E_{j} \\
A_{B 3}=\sum_{k=1}^{n} F_{k}
\end{gathered}
$$

where:

$D_{i}(i=1,2,3,4 . . n)$ stands for the amount of money billed on MD customers, $E_{j}(j=1,2,3,4 \ldots n)$ stands for the amount of money billed on metered non-MD customers, $F_{k}(k=1,2,3,4 . . n)$ stands for the amount of money billed on unmetered non-MD customers, and $\mathrm{n}=$ number of customers in the network area.

\section{5.) Revenue collection in the network area}

The algebraic sum of the total amount of money collected from MD customers $\left(A_{C 1}\right)$, metered non-MD customers $\left(A_{C 2}\right)$, and unmetered non-MD customers $\left(\mathrm{A}_{\mathrm{C} 3}\right)$ gives the net amount of money collected $\left(\mathrm{N}_{\mathrm{AC}}\right)$ in the network area. Thus,

$$
\begin{aligned}
& N_{A C}=\sum_{h=1}^{n=3} A_{C h} \\
& A_{C 1}=\sum_{x=1}^{n} P_{x} \\
& A_{C 2}=\sum_{y=1}^{n} Q_{y} \\
& A_{C 3}=\sum_{z=1}^{n} R_{z}
\end{aligned}
$$

where:

$P_{x}(x=1,2,3, \ldots n)$ is the amount of money collected from MD customers, $Q_{y}(y=1,2,3, . . n)$ is the amount of money collected from metered non-MD customers, $R_{z}(z=1,2,3, \ldots n)$ is the amount of money collected from unmetered non-MD customers, and $\mathrm{n}=$ number of customers in the network area respectively.

\section{6.) Collection efficiency}

The ratio of net amount of money collected $\left(\mathrm{N}_{\mathrm{AC}}\right)$ to net amount of money billed $\left(\mathrm{N}_{\mathrm{AB}}\right)$ is known as the collection efficiency. From Eq.s (13) and (17), the collection efficiency $(\delta)$ is obtained as; 


$$
\delta=\frac{N_{A C}}{N_{A B}}=\frac{\sum_{h=1}^{n=3} A_{C h}}{\sum_{m=1}^{n=3} A_{B m}}
$$

\section{RESULTS AND DISCUSSION}

\section{7.) $A T C \& C$ losses}

Using Eqs. (4), (12), and (21), the mathematical model for appraisal of the ATC\&C losses $(\alpha)$ of the network area is obtained as;

$$
\alpha=\{1-(\Gamma \times \delta)\} \times 100 \%=\left\{1-\left(\frac{\sum_{i=1}^{n=3} E_{B i}}{\sum_{i=1}^{\omega} K_{i}-\sum_{j=1}^{\omega} M_{j}} \times \frac{\sum_{h=1}^{n=3} A_{C h}}{n=3} A_{B m}\right)\right\} \times 100 \%
$$

The net input energy and net energy sales (billed) for the period under review are shown in Table 2, while Figure 3 shows a chart comparing them. Furthermore, the results of the billing efficiencies computed using Eq. (12) are shown in Table 3. According to Table 2, the network area received the highest amount of energy in August, followed by October, while the least was received in July. The billing efficiencies for these months according to Table 3 are 0.7884, 0.9026, and 0.8658 respectively. This means that the Area Office was unable to bill $21.16 \%, 9.74 \%$, and $13.42 \%$ of the net energy received in August, October, and July respectively.

The month with the highest billing efficiency was December, which is 0.9555 . In this month, only $4.45 \%$ of the net energy received was lost. The average billing efficiency during the study period is $89.73 \%$, which entails that about $10.27 \%$ of the energy received was recorded as lost. These losses could be as a result of transformation losses, overloading of substation equipment, apparatus, and existing lines, and lack of upgrading of old equipment and lines (R-APDRP, 2009; Shahi, 2011). Other contributing factors include irregularities in metering and meter reading, and theft by direct connection to the lines (Khobragade and Meshram, 2014; Shahi, 2011).

\begin{tabular}{|c|c|c|c|c|c|c|}
\hline Designation & July & August & September & October & November & December \\
\hline Net input energy in $\mathrm{kWh}$ & $9,870,077$ & $12,118,562$ & $10,267,402$ & $10,706,711$ & $10,245,435$ & $10,105,483$ \\
\hline Net sales in $\mathrm{kWh}$ & $8,545,113.00$ & $9,554,110.98$ & $9,645,525.56$ & $9,663,966.27$ & $9,548,523.93$ & $9,655,817.52$ \\
\hline
\end{tabular}

Table 2: Net Input Energy and Net Energy Sales of the Network Area (2019).

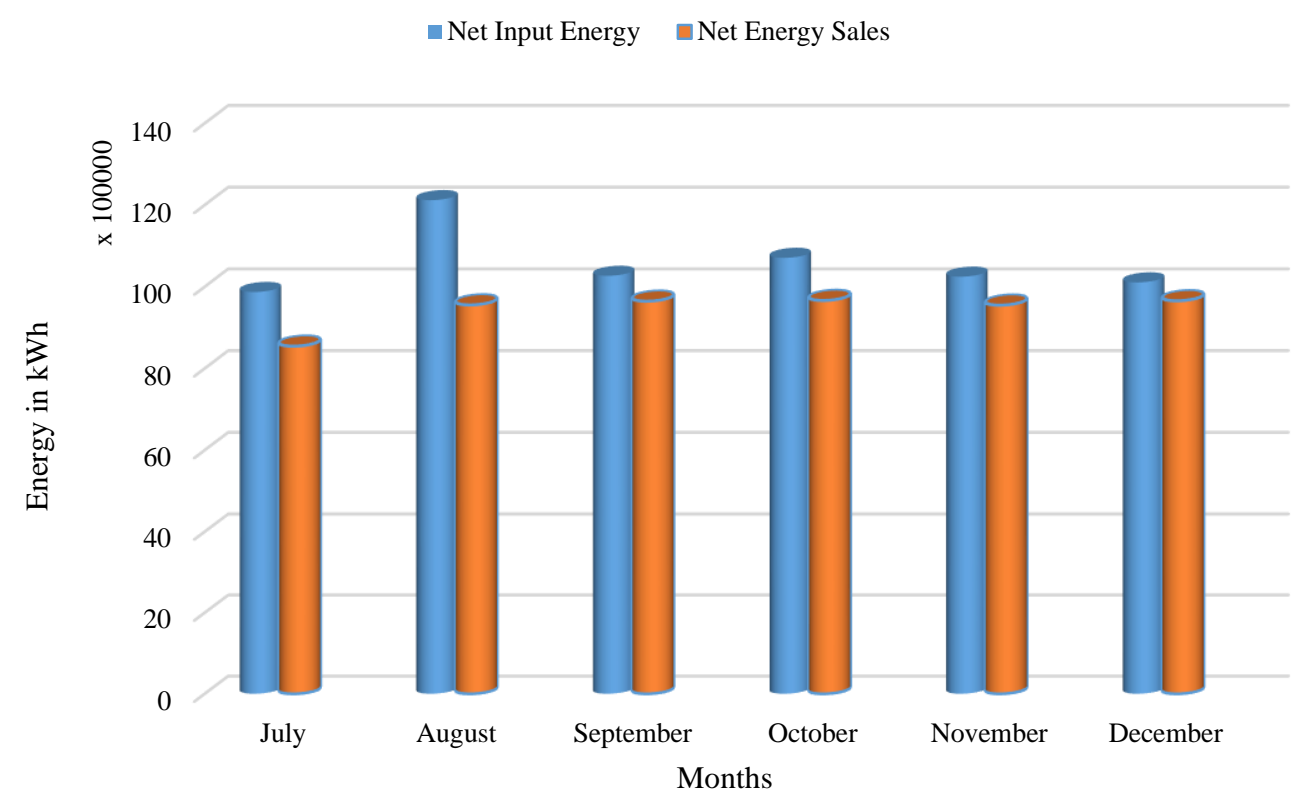

Figure 3: Net input energy and net energy sales (billed) of the network area.

Table 3: Billing Efficiency of the Network Area.

\begin{tabular}{lcccccc}
\hline Designation & July & August & September & October & November & December \\
\hline Billing Efficiency & 0.8658 & 0.7884 & 0.9394 & 0.9026 & 0.9320 & 0.9555 \\
\hline
\end{tabular}


The net amount of money billed and the net amount of money collected for the period under study and their collection efficiencies computed using Eq. (21) are shown in Tables 4 and 5 respectively. From Table 4, it can be seen that the highest amount of money was billed and collected in December. Despite the large amount of energy received in August as evident in Table 2, it was the month in which the Area Office recorded the lowest collection efficiency (0.7763), while the highest collection efficiency was recorded in September (0.8919). This means that the Area Office was unable to collect $22.37 \%$ and $10.81 \%$ of its revenues in August and September respectively. The average collection efficiency for the period under consideration is $84.80 \%$, which entails that the Area Office was unable to recover $15.20 \%$ of revenues from its customers.
Table 6 presents the summary of energy delivered, energy billed (sales), and revenue collection for July 2019, according to the cluster of customers (MD, metered non-MD, and unmetered non-MD). Figure 3 and Figure 4 are provided for ease of comparison of the net energy received and the net sales, and the net amount of money billed and the net amount of money collected respectively. Throughout the period, it appears that the net energy sales were less than the net energy received, and the net amount of money collected was less than the net amount of money billed.

Using Eq. (22), the billing efficiency and collection efficiency in Tables (3) and (5) gave the ATC\&C losses presented in Table 7.

Table 4: Net amount of money billed and collected.

\begin{tabular}{ccccccc}
\hline Designation & July & August & September & October & November & December \\
& & & & & \\
\hline Net amount billed in (N) & $264,081,229.80$ & $323,459,431.65$ & $258,991,609.19$ & $303,095,457.23$ & $308,046,545.81$ & $359,391,701.17$ \\
Net amount collected (N) & $234,536,188.90$ & $251,116,840.66$ & $230,985,491.62$ & $262,067,607.85$ & $254,254,126.36$ & $302,461,981.72$ \\
\hline
\end{tabular}

Table 5: Collection efficiency of the network area.

\begin{tabular}{lcccccc}
\hline Designation & July & August & September & October & November & December \\
\hline Collection Efficiency & 0.8881 & 0.7763 & 0.8919 & 0.8646 & 0.8254 & 0.8416 \\
\hline
\end{tabular}

Table 6: Energy delivered, energy billed, and ATC\&C losses for July 2019.

\begin{tabular}{|c|c|c|c|c|c|c|c|}
\hline Designation & Total & $\begin{array}{c}\text { Efficiency } \\
\text { in Unity }\end{array}$ & $\begin{array}{c}\text { Efficiency } \\
\text { in } \% \\
\end{array}$ & $\begin{array}{c}\text { ATC \& C } \\
\text { Losses }\end{array}$ & MD & $\begin{array}{l}\text { Metered } \\
\text { non-MD }\end{array}$ & $\begin{array}{c}\text { Un-metered } \\
\text { non-MD }\end{array}$ \\
\hline Energy Delivered in kWh & $9,870,077$ & 1 & $100.00 \%$ & \multirow{4}{*}{$23.11 \%$} & $5,922,046$ & $1,875,315$ & $2,072,716$ \\
\hline Energy Billed in $\mathrm{kWh}$ & $8,545,113$ & 0.8658 & $86.58 \%$ & & $5,127,068$ & $1,623,571$ & $1,794,474$ \\
\hline Billing in & $264,081,229.80$ & 1 & $100.00 \%$ & & $158,448,737.86$ & $50,175,433.65$ & $55,457,058.25$ \\
\hline Collection in & $234,536,188.90$ & 0.8881 & $88.81 \%$ & & $140,721,713.33$ & $44,561,875.89$ & $49,252,599.66$ \\
\hline
\end{tabular}

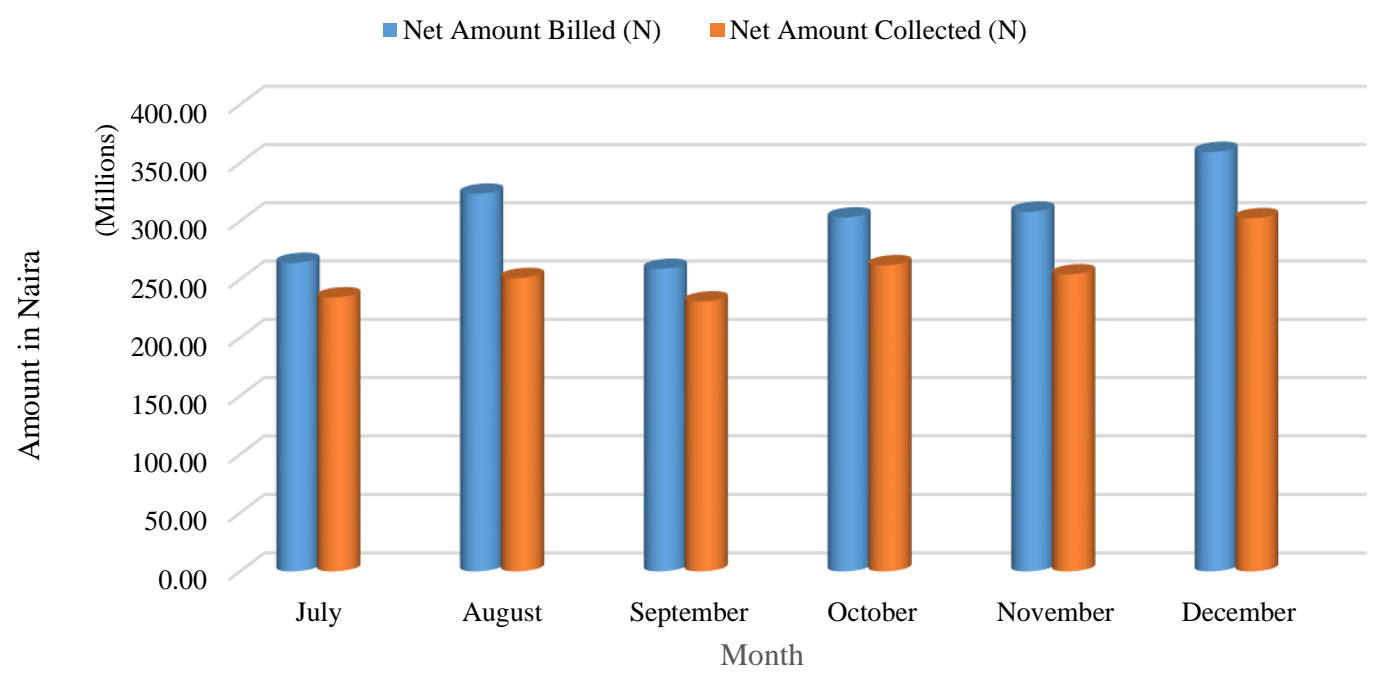

Figure 4: Revenue collection for the network area.

Table 7: ATC\&C losses of the network area.

\begin{tabular}{lcccccc}
\hline Designation & July & August & September & October & November & December \\
\hline ATC\&C Losses & $23.11 \%$ & $38.79 \%$ & $16.22 \%$ & $21.96 \%$ & $23.08 \%$ & $19.59 \%$ \\
\hline
\end{tabular}


Figure 5 shows the trend of ATC\&C losses for the period under consideration. It is obvious that the ATC\&C losses did not follow a consistent pattern. An initial $23.11 \%$ in July, then a significant shoot-up in August (38.79\%), then a drastic drop in September (16.22\%), another increase in October (21.96\%) and November $(23.08 \%)$ respectively, and consequent dropping in December (19.59\%). The average ATC\&C losses during this period are $23.79 \%$.

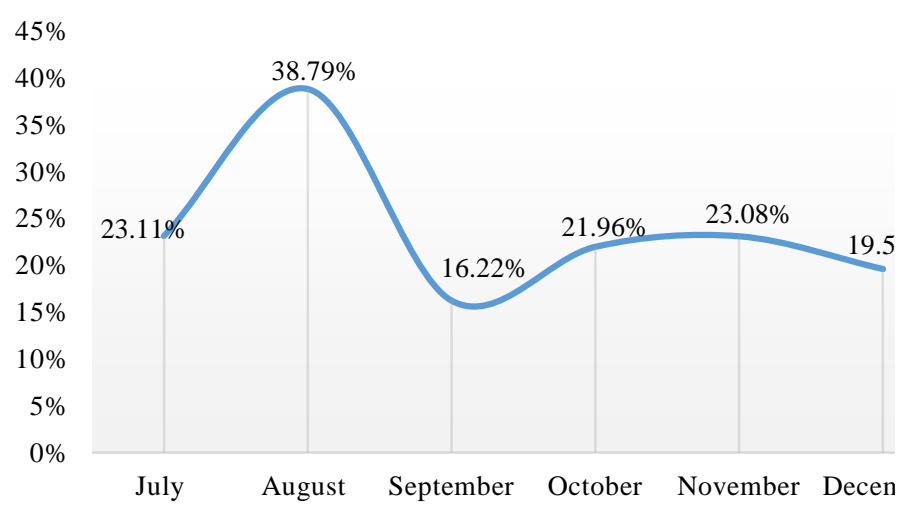

Figure 5: Trend of ATC\&C losses of the network area.

\section{CONCLUSION}

This paper analysed the Aggregate Technical, Commercial and Collection (ATC\&C) losses in Life Camp Area Office's network of Abuja Electricity Distribution Company Plc, Nigeria. The customers in the network area were grouped as maximum demand and non-maximum demand customers (metered and unmetered). On that basis, mathematical analysis was carried out for appraisal of the ATC \&C losses for a period of six months (July to December 2019). The average billing efficiency, collection efficiency and ATC\&C losses for the period under review were found to be $89.73 \%, 84.80 \%$, and $23.79 \%$ respectively. The utility (AEDC) will have to concentrate on reducing these losses to ensure that the efficiency of the distribution network is improved and the cost of operation is considerably reduced.

Some of the measures to curtail these losses include; conductor replacement within the network, network reconfiguration, prevention of leakages through insulators, effective and efficient management of distribution substations, severe penalties for energy theft, correct billing and timely delivery of bills, use of appropriate current/voltage transformers and meter current/voltage ratios, load balancing and load management, improvement of joints and connections, and regular maintenance of the apparatus.

This paper is expected to serve as a tool to power system engineers, utilities, and energy policy makers as it provides the true picture of revenue and energy loss conditions of the distribution system. Future studies should consider developing computer programs to fast-track evaluation of ATC\&C losses in the distribution network as an advancement to this work. $\mu=$ net input energy

$E_{\text {in }}=$ total energy received

$E_{\text {out }}=$ total energy exported

$K_{i}=$ boundary meters registering import of energy

$M_{j}=$ boundary meters registering export of energy

$\omega=$ number of feeders in the network

$E_{B i}=$ algebraic sum of the energy billed in the network area

$E_{B 1}=$ total energy billed on MD customers

$E_{B 2}=$ total energy billed on metered non-MD customers

$E_{B 3}=$ total energy billed on unmetered non-MD customers

$N_{E B}=$ net energy sales/billed

$A_{i}=$ energy billed on MD customers

$B_{j}=$ energy billed on metered non-MD customers

$C_{k}=$ energy billed on unmetered non-MD customers

$n=$ number of customers in the network area

$\Gamma=$ billing efficiency

$A_{B m}=$ algebraic sum of the amount of money billed in the network area

$A_{B 1}=$ total amount of money billed on MD customers

$A_{B 2}=$ total amount of money billed on metered non-MD customers

$A_{B 3}=$ total amount of money billed on unmetered non-MD customers

$N_{A B}=$ net amount of money billed in the network area

$D_{i}=$ amount of money billed on MD customers

$E_{j}=$ amount of money billed on metered non-MD customers

$F_{k}=$ amount of money billed on unmetered non-MD customers $A_{C h}=$ algebraic sum of the money collected in the network area $A_{C l}=$ total amount of money collected from MD customers

$A_{C 2}=$ total amount of money collected from metered non-MD customers

$A_{C 3}=$ total amount of money collected from unmetered nonMD customers

$N_{A C}=$ net amount of money collected in the network area.

$P_{x}=$ amount of money collected from MD customers

$Q_{y}=$ amount of money collected from metered non-MD customers

$R_{z}=$ amount of money collected from unmetered non-MD customers

$\delta=$ collection efficiency

$\alpha=\mathrm{ATC} \& \mathrm{C}$ losses

\section{REFERENCES}

Alam, M.; S. M. Yasin and M. Gain. (2014). A Review of Losses in Distribution Sector and Minimization Techniques. International Journal of Advanced Research in Electrical, Electronics and Instrumentation Engineering, 3(10), 1243012437.

Alamin, A. A. (2012). Electrical Power Distribution Losses in Sudan. Unpublished B.Sc Thesis, Deaprtment of Electrical and Electronic Engineering, University of Khartoum, Sudan.

Amaranatha, D.; R. Madhan and M. P. Lalitha. (2015). Power Loss Reduction in Radial Distribution Systems by Optimal Capacitor Placement to Distribution Transformers. International Journal of Engineering and Applied Sciences, 2(11), 89-95. 
Anumaka, M. C. (2012). Analysis of Technical Losses in Electrical Power System (Nigerian 330kV Network as a Case Study). IJRRAS, 12(2), 320-325.

Ayamolowo, O. J.; E. Buraimoh and A. O. Salau. (2019). Nigeria Electricity Power Supply System: The Past, Present and the Future. IEEE PES/IAS PowerAfrica, Abuja, Nigeria, 64-69, USA: IEEE.

Gosh, S. (2012). Loss Reduction and Efficiency Improvement: A Critical Appraisal of Power Distribution Sector in India. International Journal of Modern Engineering Research, 2(5), 3292-3297.

Inan, H.; J. Boston and M. Sheibe. (2014). Systems Loss Reduction. Teachnical Report, Mark Scheibe, Maquoketa Valley Electric Cooperative, Iowa, USA.

Independent Energy Watch Initiative. (2016). The Nigerian Electricity Tariff and the ATC and C Loss Paradox: Are we paying for Services or Losses? Abuja. Retrieved January 11, 2020, from http://iwin.org.ng/index.php/ndph/item/2235-the-nigerianelectricity-tariff-and-the-atc-c-loss-paradox-are-we-payingfor-services-or-losses

Khobragade, S. N., and Meshram, D. B. (2014). Commercial Loss Reduction Techniques in Distribution Sector - An Initiative by MSEDCL. International Journal of Advanced Research in Electrical, Electronics and Instrumentation Engineering, 3(1), 6889-6891.

Kirankumar, M.; K. V. Sairam and R. Santosh. (2013). Methods to Reduce Aggregate Technical and Commercial (ATC \& C) Losses. International Journal of Engineering Trends and Technology, 4(5), 1501-1505.

Komolafe, O. M.; and Udofia, K. M. (2020). Review Of Electrical Energy Losses in Nigeria. Nigerian Journal of Technology (NIJOTECH), 39(1), 246-254. doi:http://dx.doi.org/10.4314/njt.v39i1.28

Mahmood, M.; O. Shivan, P. Kumar and G. Krishnan. (2014). Real-Time Study on Technical Losses in Distribution System. International Journal of Advanced Research in Electrical, Electronics and Instrumentation Engineering, 3(1), 131-137.

Mam, M.; A. Joseph and A. Singh. (2014). A Case Study on Issues and Challenges faced during Strengthening of a Distribution Unit by Reducing Aggregate Technical and Commercial Losses. International Journal of Electrical and Electronics Research, 2(1), 36-40.
Navani, J. P.; N. K. Sharma and S. Sapra. (2014). A Case Study of Analysis of Technical and Non-Technical Losses in Power System and its Impact on power Sector. International Journal of Advances in Engineering Science and Technology, 1(2), 137-146.

NERC. (2015). Amended Multi-Year Tariff Order MYTO2.1 for the Period April 2015 to December 2018. Abuja, Nigeria: Nigerian Electricity Regulatory Commission.

Nwohu, M. N.; A. S. Mohammed and U. A. Dodo. (2017). Methodology for Evaluation of Aggregate Technical, Commercial and Collection Losses in a Typical Radial Distribution System. International Journal of Research Studies in Electrical and Electronics Engineering, 3(2), 1-10. doi:http://dx.doi.org/10.20431/2454-9436.0302001

Okechukwu, N. (2019). Nigeria's power sector losses growing at N474bn annually - AFD. Abuja, Nigeria: The Punch. Retrieved October 9, 2020, from https://punchng.com/nigerias-power-sector-losses-growingat-n474bn-annually-afd/

Power Distribution Management. (2016). Aggregate Technical and Commercial Loss. Retrieved January 2, 2020, from www.powerdistributionmanagement.blogspot.com/2014 /12/aggregate-technical-and-commercial-loss.html

Rakhra, G. S. (2013). Analysis of Commercial and Administrative Losses in Radial Distribution. International Journal of Advanced Communication Engineering, 1(1), 3137.

R-APDRP. (2009). Methodology for Establishing Baseline AT \& C Losses. A Report on the Restructured Accelerated Power Development and Reforms Programme (R-APDRP) of Governement of India, Power Finance Corporation Limited, India.

Sandhu, I. S.; and Maninder. (2013). Analysis of Losses in Power System and Economic Consequences in the Power Sector. International Journal of Enhanced Research in Science Technology \& Engineering, 2(7), 90-98.

Shahi, R. V. (2011). Presentation on Electricity Distribution Losses and Concept of Aggregate Technical and Commercial Loss. Lecture Presentation, Energy Infratech Pvt. Ltd., New Delhi, India

Singh, A. (2013). Computation of Aggregate Technical and Commercial Losses with the help of Single-Line Diagrams of Dakpathar Distribution Division. Summer Training Report, MBA Power Management Programme, Maharshi Dayanand University, Rohtak, India. 